\title{
Erratum
}

\section{Prevalence, Safety, and Effectiveness of Oral Anticoagulant Use in People with and without Dementia or Cognitive Impairment: A Systematic Review and Meta-Analysis}

Laura Fanning, Taliesin E. Ryan-Atwood, J. Simon Bell, Atte Meretoja, Kevin P. McNamara, Pēteris Dārziņš, Ian C.K. Wong, Jenni Ilomäki

[Journal of Alzheimer's Disease, 65(2) (2018), 489-517, DOI 10.3233/JAD-180219]

https://content.iospress.com/articles/journal-of-alzheimers-disease/jad180219

Table 3 was accidentally printed twice, with the correct Table 2 (starting on page 502) missing from the published article. The correct Table 2 is printed below. 


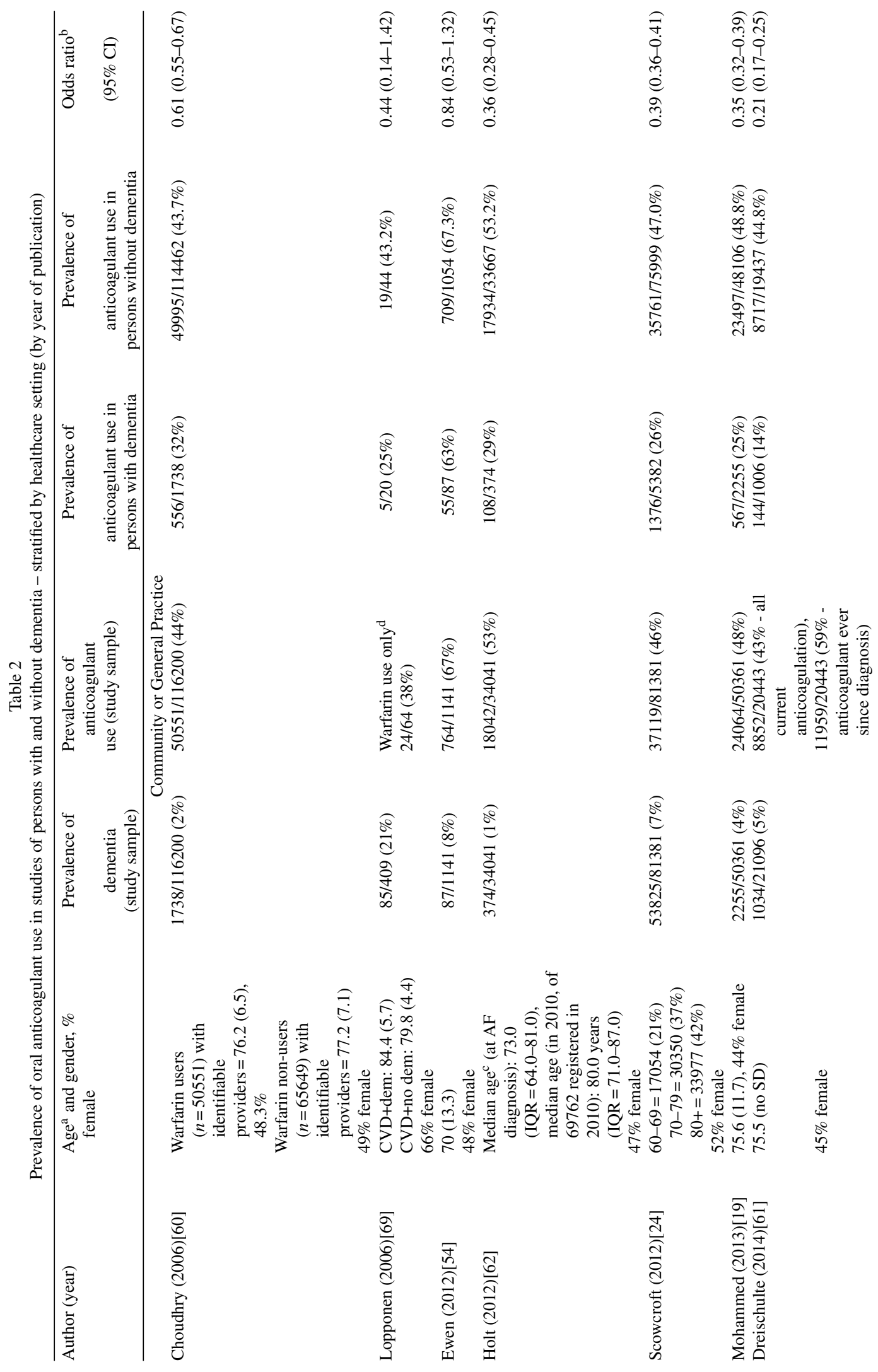




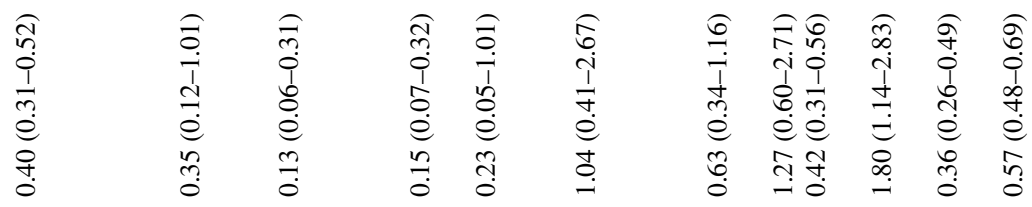

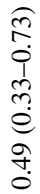

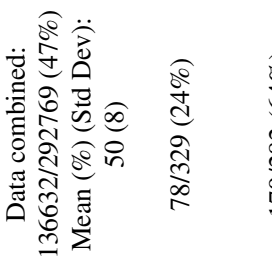

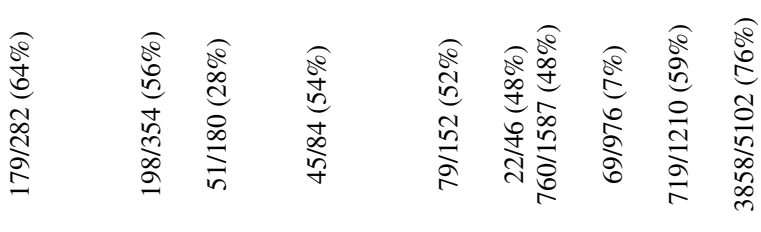

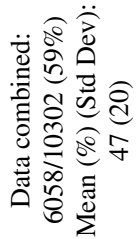

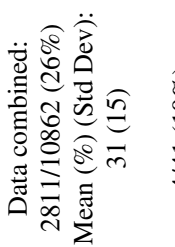

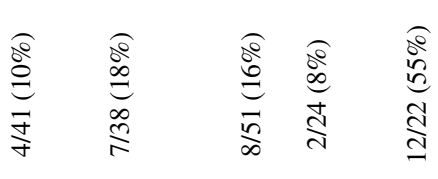

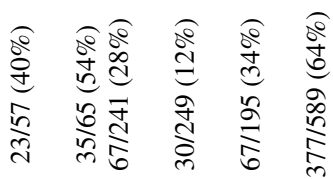

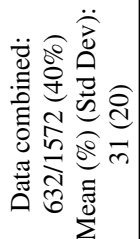

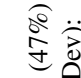

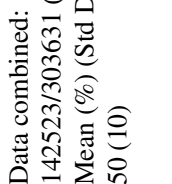

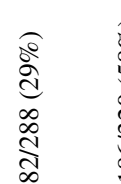

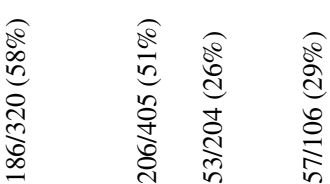

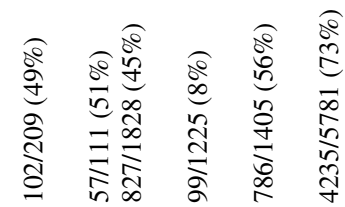

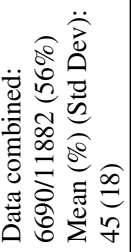

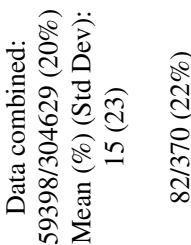

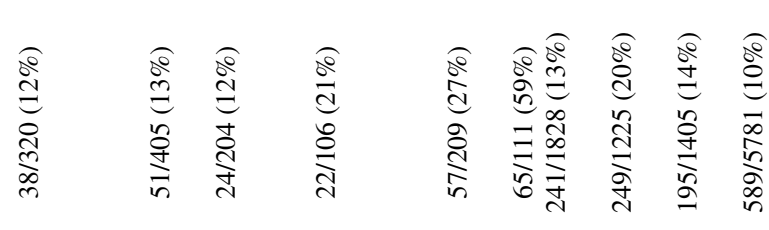

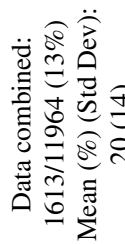

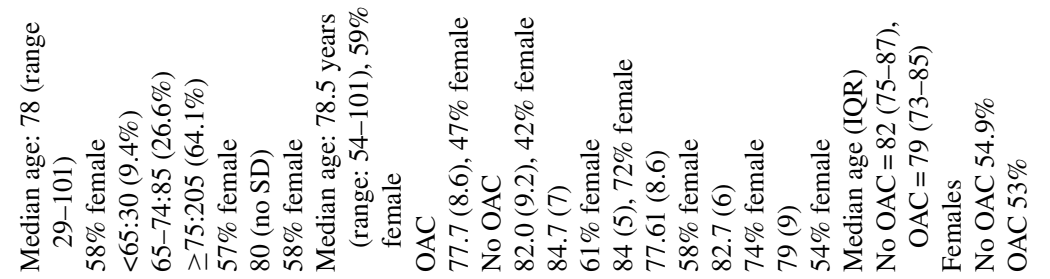

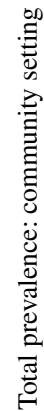

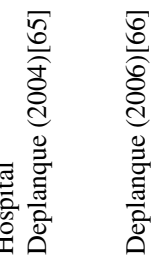

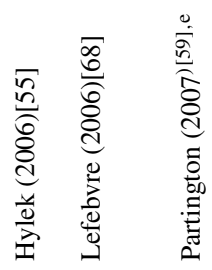

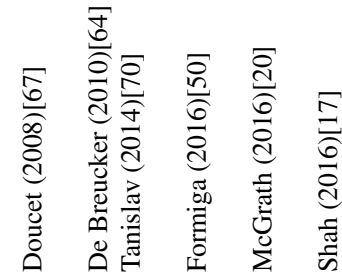

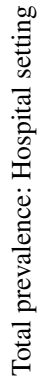




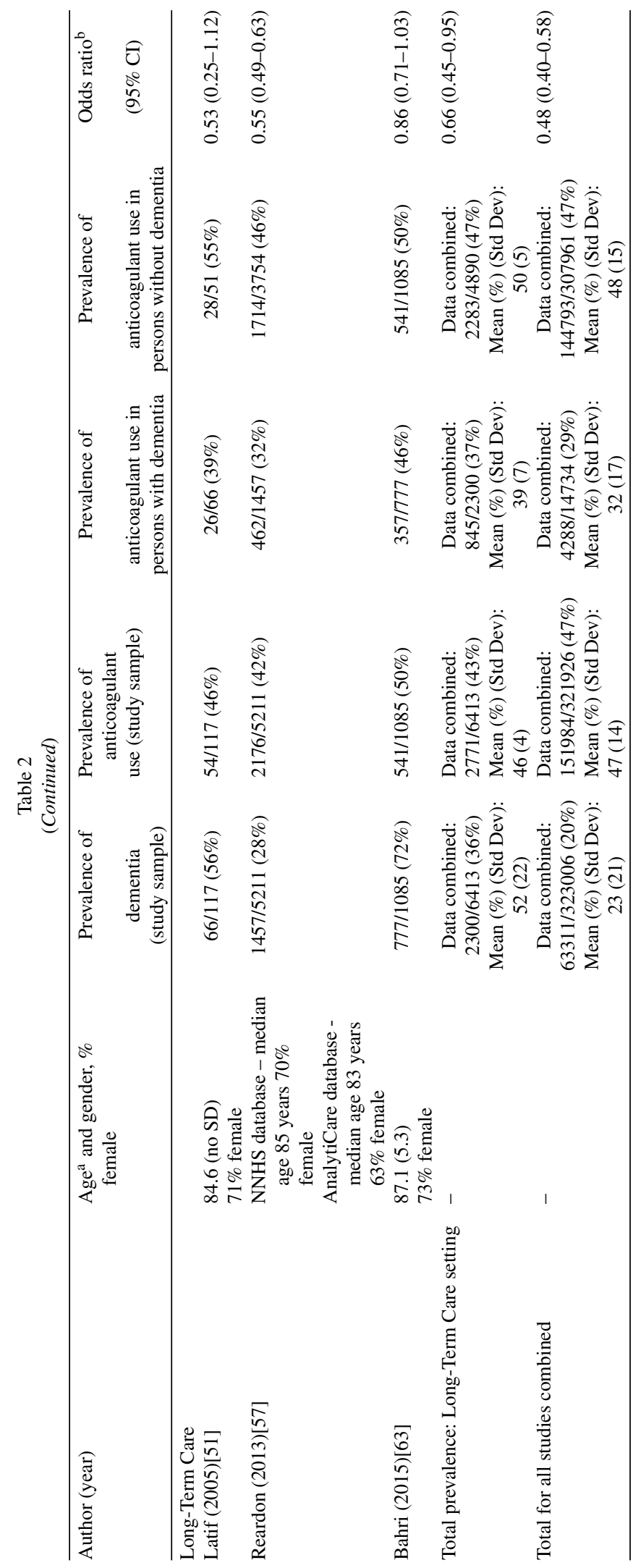

